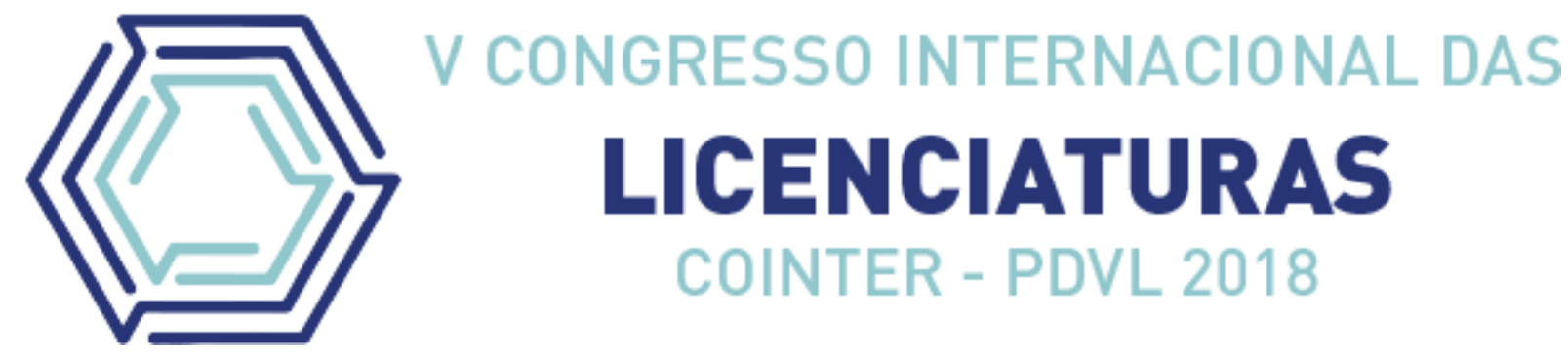

\title{
A ETNOFARMACOLOGIA COMO FERRAMENTA DE EDUCAÇÃO AMBIENTAL EM UMA COMUNIDADE RURAL
}

\section{ETHNOPHARMACOLOGY AS A TOOL FOR ENVIRONMENTAL EDUCATION IN A RURAL COMMUNITY}

\author{
Maria Givânia Gonçalves; Maísa Fernanda Dos Santos Barbosa. \\ Apresentação: Comunicação Oral
}

DOI: $\underline{\text { https://doi.org/10.31692/2358-9728.VCOINTERPDVL.2018.00009 }}$

\begin{abstract}
Resumo (em Português ou Espanhol)
Plantas medicinais são as mais antigas 'armas' empregadas pelo homem no tratamento de enfermidades e continuam sendo importantes na terapêutica contemporânea na formulação de medicamentos, tanto compondo os fitoterápicos, quanto servindo de base na formulação de moléculas sintéticas. Neste estudo foi realizado um trabalho de educação ambiental em uma comunidade ruralutilizando a Etnofarmacologia como ferramenta pedagógica. A primeira etapa do estudo consistiu em uma pesquisa feita com os moradores da comunidade através da aplicação de um questionário semiestruturado sobre o conhecimento prévio dos entrevistados sobre plantas medicinais, espécies, formas de uso, etc. No final do questionário os entrevistados foram indagados sobre o interesse na implantação de uma horta medicinal comunitária, onde todos demonstraram interesse. Na última etapa do estudo, foi construída a horta medicinal comunitáriacom as plantas mencionadas no questionário, sendo inclusive os moradores os doadores das mudas utilizadas. Na horta foram colocadas informações sobre as plantas cujo potencial medicinal tinha sido corroborado empiricamente pela literatura. Dentre elasasmais utilizadas foram: Hortelã (Menthasp), Erva Cidreira (Matricaria recutita) e Camomila (Lippia Alba). Esses resultados demonstraram um fato preocupante, a proporção de espécies exóticas foi bem maior que o de espécies nativas. Todavia, foi possível concluir que o estudo foi de grande importância para toda a polulação local porque, além de contribuir para a promoção da saúde na comunidade, teve uma abordagem pedagógica construtivista. Uma vez queo conhecimento prévio dos moradores foi valorizado e validado, a construção da horta teve uma participação ativa da comunidade, facilitando a construção de novos "saberes" e desta forma modificando a realidade local.
\end{abstract}

Palavras-Chave: Fitoterapia, Saúde Pública, Sabedoria Popular, Construtivismo.

\begin{abstract}
Medicinal plants are the oldest 'guns' used by man in the treatment of diseases and continue to be important in contemporary therapeutics in the formulation of medicines, both composing phytotherapics and serving as the basis for the formulation of synthetic molecules. In this study, environmental education work was carried out in a rural community using ethnofarmacology as a pedagogical tool. The first stage of the study consisted of a research
\end{abstract}


done with the residents of the community through the application of a semi-structured questionnaire about the prior knowledge of the interviewees about medicinal plants, species, forms of use, etc. At the end of the questionnaire, the interviewees were asked about the interest in the implementation of a community medicine garden, where everyone showed interest. In the last stage of the study, the community medicinal vegetable garden was built with the plants mentioned in the questionnaire, and the residents were also the donors of the seedlings used. In the garden were placed information on plants whose medicinal potential had been empirically corroborated by the literature. Among the most used were: Mint (Menthasp), Erva Cidreira (Matricaria recutita) and Camomila (Lippia Alba). These results showed a worrying fact, the proportion of exotic species was much higher than that of native species. However, it was possible to conclude that the study was of great importance for all local polio because, in addition to contributing to health promotion in the community, it had a constructivist pedagogical approach. Once the previous knowledge of the residents was valued and validated, the construction of the garden had an active participation of the community, facilitating the construction of new "knowledge" and in this way modifying the local reality.

Keywords: Keywords: Phytotherapy, Public Health, Popular Wisdom, Constructivism.

\section{Introdução}

A Etnofarmacologia é a ciência que estuda o conhecimento popular sobre fármacos dedeterminados grupos étnicos einvestiga as possibilidades e hipóteses referentes aos conhecimentos tradicionais, buscandoempiricamente o que provoca os efeitos dos "fármacos tradicionais" (SILVA, 2011). Ela pode ser utilizada como um instrumento que venha a servir para a exploração interdisciplinar de agentes biologicamente ativos (partes ou produtos de vegetais, animais, etc.) tradicionalmente empregados pelo homem (SANTOS, 2010).

Um ramo demasiadamente explorado é a busca por novas moléculas e princípios ativos através da investigação do conhecimento tradicional (TORRES; SILVA, 2009), mas uma vertente pouco explorada e fundamental em questão de saúde pública é a utilização da Etnofarmacologia como ferramenta para a educação ambiental, abordagem que pode ser feita tanto em escolas como em comunidades, sendo elas rurais ou urbanas (LIMA; SANTOS e OLIVEIRA, 2014).

A fitoterapia permite que o ser humano se reconecte com o meio ambiente e, acessando o "poder" da natureza, tem a possibilidade de ajudar o seu organismo a normalizar suas funções fisiológicas, fortalecer o seu sistema imune, promover a desintoxicação, etc (RODRIGUES, 2013).

Além disso, uma questão muito importante na educação ambiental é a abordagem

pedagógica, visto que ela é fundamentalno processo ensino-aprendizagem. Logo, a 
Etnofarmacologiaemerge como uma ferramenta onde se pode trabalhar sob o viés do construtivismo dois dos quatro temas transversais que, de acordo com os Parâmetros Curriculares Nacionais (PCNs), são fundamentais. Estes dois temas são: "Saúde" e "Ser Humano e Ambiente" (SOUSSAN, 2003; OLIVEIRA, 2016).

A abordagem Etnofarmacológica nas comunidades tradicionais estimula o respeito ao meio ambiente e ao modus vivendi dessas populações, sendo essencial para o desenvolvimento sustentável e manutenção da sociobiodiversidade (ELISABETSKY, 2003). As plantas ditas medicinais sempre foram utilizadas pelas civilizações antigas e continuam sendo atualmente, sendo primordiais para a saúde da humanidade. Isto porque estas "armas" são empregadas pelo homem no tratamento de enfermidades de todos os tipos, isto é, na prevenção e/ou cura de doenças, sendo utilizadas tanto por comunidades tradicionais como pelo homem contemporâneo, estando presentes inclusive na indústria farmacêutica compondo os fitoterápicos (OLIVEIRA, 2010; MARINA, 2016).

Para (FREIRE, 1987) a educação não seria possível se não houvesse a valorização do ser humano. O papel do educador seria então possibilitar que o educando acesse o conhecimento de forma real e objetiva, isto é, vivenciasse a experiência concreta e principalmente, sentisse prazer ao vivenciá-la. Além disso, ele defende que sem isso não pode haver a ação humana, ou seja, o educandosó se torna atuante na sociedade quando tratado como um ser cheio de "capacidades", um ser que pode não apenas acessar o mundo simplesmente, mas pode também ir além e modificá-lo. Logo, através de uma abordagem pedagógica construtivista é possível modificar a realidade das pessoas, pois elas adquirem uma condição de "pertencimento" sobre o conhecimento adquirido.Vale ressaltar que muitas não têm recursos para comprar medicamentos caros e o Sistema Único de Saúde (SUS) é cheio de carências e falhas.Com isto, as plantas medicinais se tornam muitas vezes a única alternativa de tratamento e o conhecimento sobre suas propriedades tem o poder de modificar esta realidade.

Este trabalho foi executado não com o objetivo de investigar a possibilidade de encontrar novas moléculas e princípios ativos para a indústria farmacêutica, mas sim de realizar um trabalho de educação ambiental, utilizando a Etnofarmacologia como ferramenta pedagógica para transformar a realidade dos moradores do Sítio Destino, uma comunidade sertaneja do interior do estado de Pernambuco, Brasil.

\section{Fundamentação Teórica}


Segundo a resolução da Diretoria Colegiada de 2004, da Agência Nacional de Vigilância Sanitária (CASTRO, 2008), fitoterápicos são medicamentos preparados exclusivamente com plantas ou partes de plantas medicinais (raízes, cascas, folhas, flores, frutas ou sementes) que possuem propriedades reconhecidas de cura e prevenção de doenças (MATOS, 2011).

O reconhecimento sobre plantas medicinais simboliza muitas vezes o único recurso terapêutico utilizados pelas famílias de muitas localidades, devido aos altos custos dos medicamentos industrializados (LOPEZ, 2015).

No Brasil o uso popular sobre plantas medicinais teve seu inicio provavelmente na préhistória, poratanto as plantas tem sido desde a antiguidade, um recurso ao alcance dos seres humanos (KAPLAN, 2016).

O Construtivismo é uma teoria de aprendizagem, que pode também ser entendida como uma ligação pedagógica, e sua principal característica é a forma de como o ser adquiri seu conhecimento e o seu apredizado, e aprende a relacionar com a interação do meio em que vive (SOUSA, 2015). Uma teoria da aprendizagem, que tem como principal foco a aprendizagem que relacionaos conhecimentosprévios do educando com os novos "saberes", para que ele possa se sentir parte do processo e assim, a construção do conhecimento é mais eficaz (BARBOSA, 2014).

Portanto de acordo com A Pedagogia do Oprimido, a Educação Ambiental crítica pode ser compreendida como uma perspectiva educativa que traz como eixo uma proposta trasformadora com relação à organização social e aos fundamentos que sustentam a relação sociedade/natureza. A Educação Ambiental é uma vertente da educação direcionada aos assuntos relacionados á interação homem-ambiente, despertando uma consciência crítica sobre os problemas ambientais. Trabalha o lado racional juntamente com o sensível e de valores, promovendo o desenvolvimento de novos valores e ações de respeito e proteção ao Meio Ambiente (SOUZA, 2016).

\section{Metodologia}

A pesquisa foi feita em três etapas. A primeira consistiu na aplicação de um questionário semi-estruturado para uma amostra de moradores de diferentes faixas etárias que residem na comunidade do Sítio Destino, que pertencente ao Município de Terra Nova.

O município está localizado na mesorregião do Sertão de Pernambuco (microrregião 
do Sertão Central) e fica a oeste da capital Recife (554 Km de distância). Possui uma população estimada em 10.185 habitantes dentro de uma unidade territorial de 296,178 Km (IBGE, 2016).

O Sitio Destino contém uma área de 60 hectares e apresenta um total de 298 pessoas, que sobrevivem por muito tempo da subsistência em estreita relação com os ecossistemas naturais. A fitossociologia que se apresenta é típica de clima semiárido, com mecanismos fisiológicos de adaptações a este ambiente, como espinhos, caules modificados para a fotossíntese e o armazenamento de água, fechamento dos estômatos nas horas quentes do dia, (ALICE, 2010). É importante ressaltar que nos últimos anos, esta região vem sofrendo diversas agressões ambientais que causam o emprobecimento do solo, dificultando mais ainda o desenvolvimento regional (IBGE, 2016).

$\mathrm{Na}$ segunda etapa do estudo foi realizada uma pesquisa bibliográfica sobre as espécies citadas pelos moradores. O objetivo foi o de investigar se estas espécies tinham alguma validação científica sobre as propriedades terapêuticas indicadas pelos moradores.

Por fim, na terceira etapa do estudo, foi construída uma horta medicinal comunitária, com informações empíricas (terapêuticas e toxicológicas) sobre as plantas utilizadas (Figura $1)$.

Figura 1- Construção da horta medicinal comunitária: A- Exemplos de algumas plantas medicinais como: Alfavaca e Babosa; B- Outros exemplos como: Mentruz e Capim-Santo; C- Algumas pessoas da comunidade construindo a horta; D- Pessoas conversando e discutindo como será feita essa horta. Fonte: Própria.
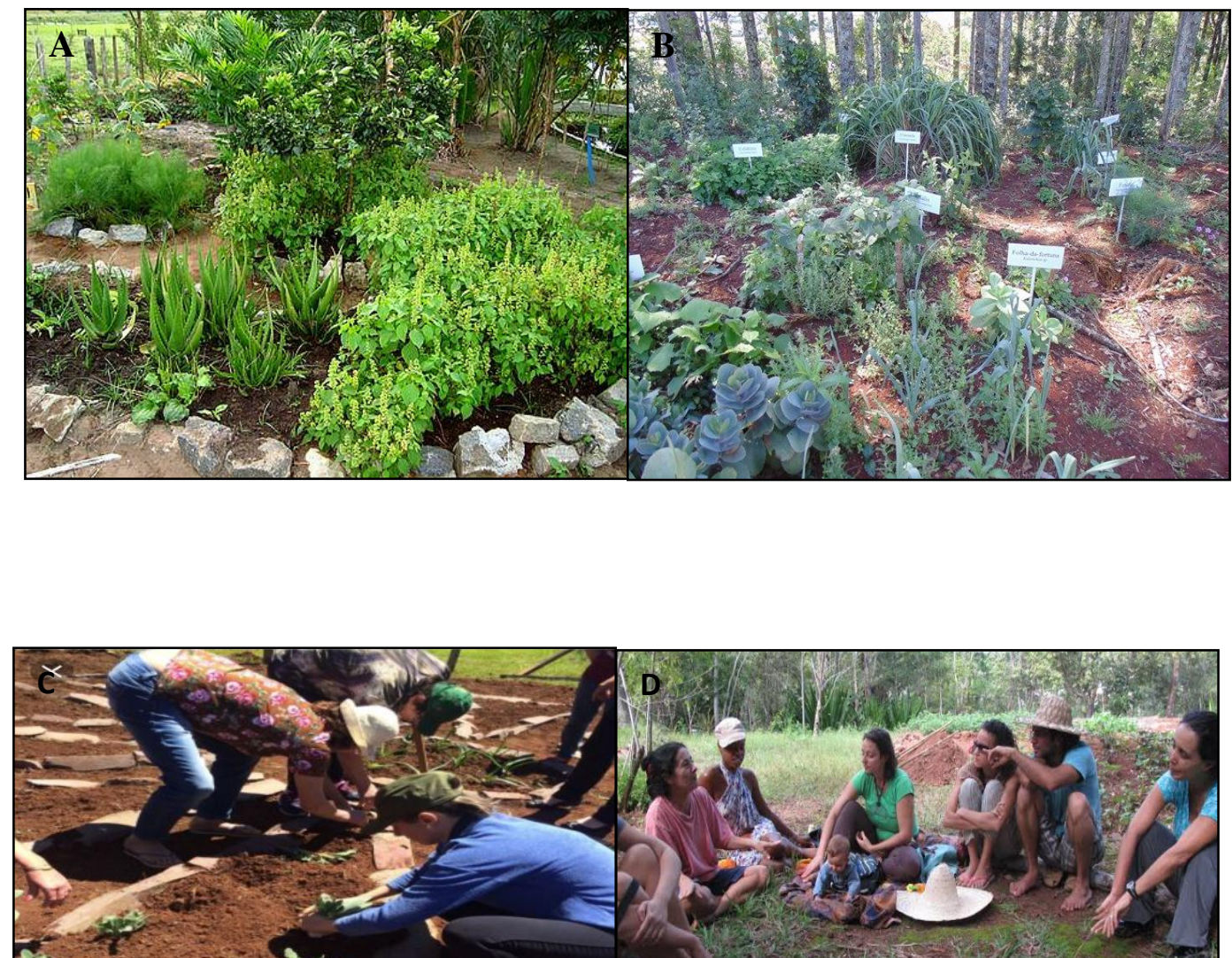


\section{Resultados e Discussão}

No presente estudo participaram um total de 30 pessoas com idades entre 10 e 75 anos, dos quais 18 eram do gênero Masculino e 12 do gênero Feminino.

$\mathrm{Na}$ tabela 1 estão listadas as espécies citadas (com seus nomes vernáculos e científicos), o número de citações e as formas de uso entre os entrevistados, bem como a validação científica sobre as propriedades terapêuticas mencionadas.

Foi possível notar que $100 \%$ dos entrevistados usa ou fez uso de algumas Plantas Medicinais, sendo as mais citadas: Hortelã, Camomila e Erva-Cidreira (Figura 2). Entre as partes mais usadas das plantas as folhas predominam (Figura 3). Observou-se também que, em relação a forma de obtenção da planta, a maioria dos entrevistados responderam que as obtém no quintal de casa e/ou nos quintais de vizinhos e amigos (Figura 4). Estes resultados refletem a importância da implantação da horta comunitária, realizada na última etapa do estudo.

Figura 2: Número de citações entre as espécies citadas nos questionários. Fonte:Própria

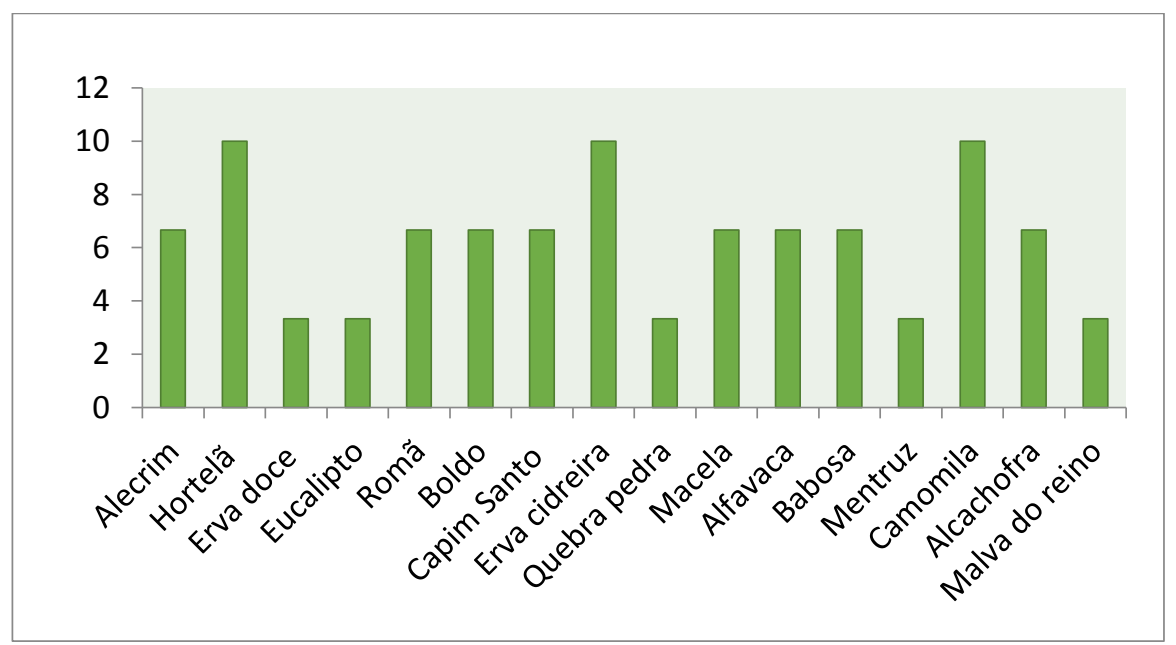

Figura 3: Porcentagem das partes (da planta) mais utilizadasentre os entrevistados. Fonte: Própria 


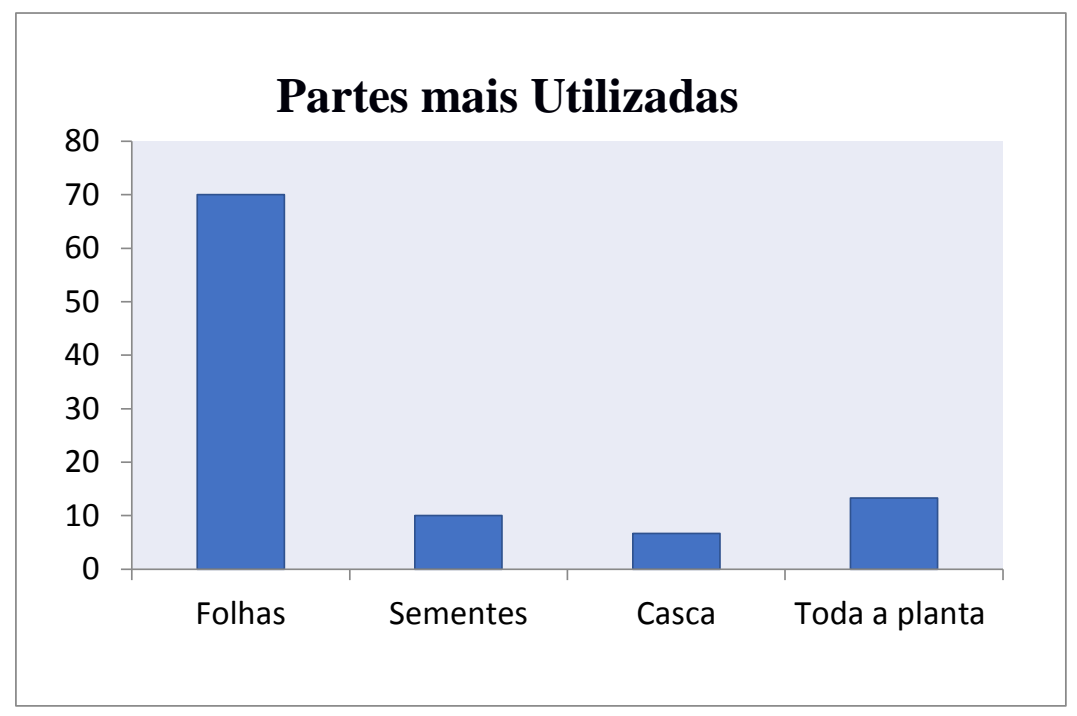

Figura 4: Percentagem das formas de obtenção das plantas entre os entrevistados. Fonte:Própria.

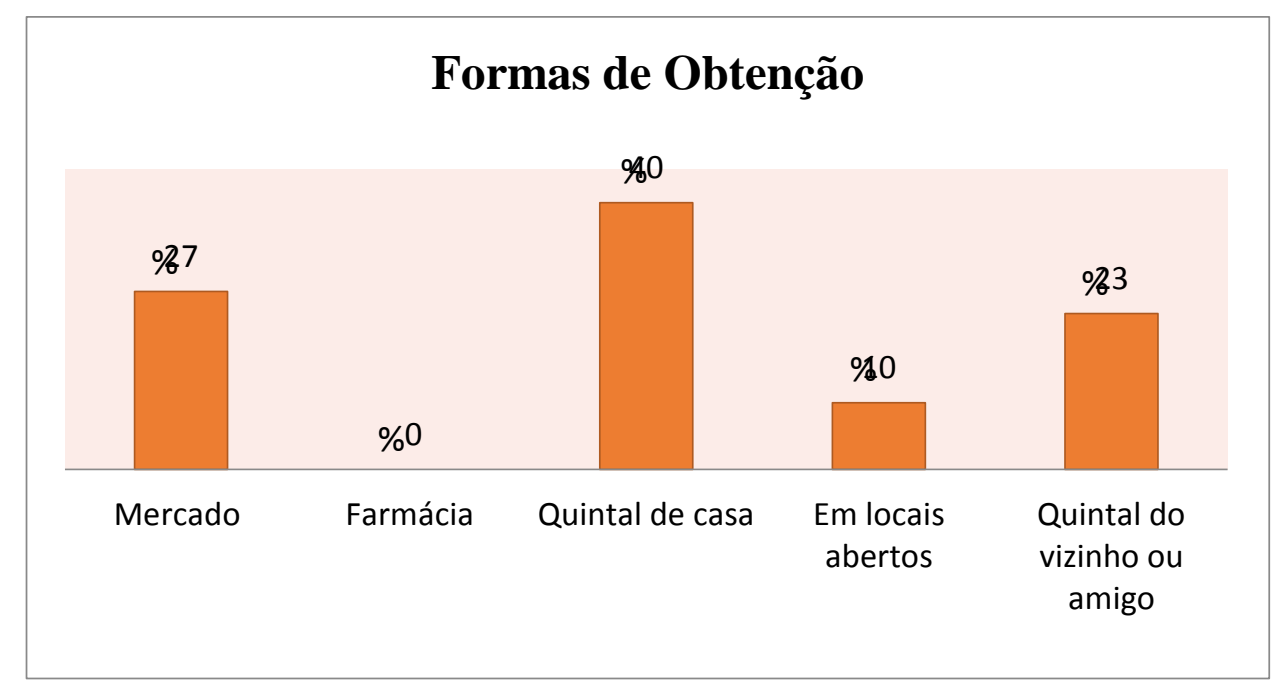

Quando os entrevistados foram questionados sobre como adquiriram tal conhecimento, ficou claro que a família domina este cenário (Figura 5). Este resultado é particularmente 
interessante porque ressalta algo que está muito bem estabelecido no Art. 205 da Constituição Federal de 1988, onde diz: "A educação, direito de todos e dever do Estado e da família, será promovida e incentivada com a colaboração da sociedade, visando ao pleno desenvolvimento da pessoa, seu preparo para o exercício da cidadania e sua qualificação para o trabalho."

Figura5- Porcentagem das fontes de aquisição do "conhecimento terapêutico" dos entrevistados. Fonte: Própria

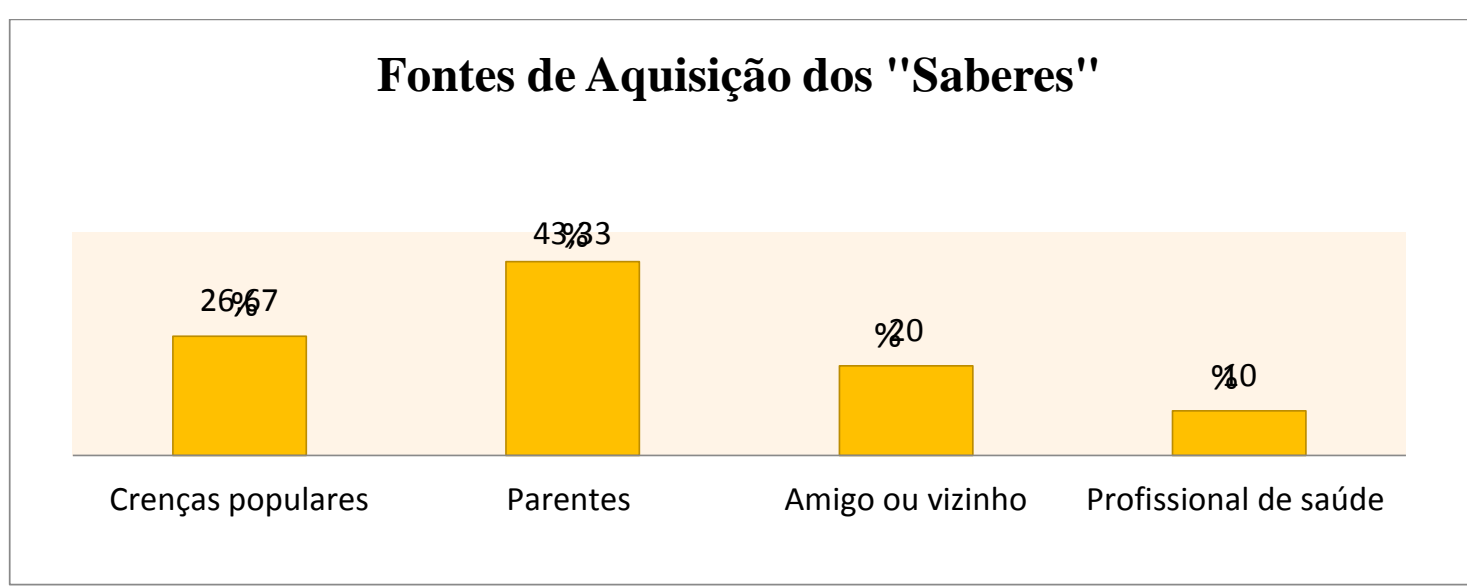

Assim como este, outros estudos obtiveram resultados que corroboram com a hipótese de que a abordagem Etnofarmacológica é uma valiosa ferramenta educacional.

(VIANA, 2016) fez um estudo sobre Educação Ambiental e constatou que a fitoterapia nem sempre se dar pela escolha entre o popular e o convencional, mas sim muitas vezes por ser a única fonte de medicamento encontradas por várias localidades. Portanto pessoas que moram em zonas rurais, muitas das vezes tem pouco acesso aos fármacos, daí constroem essa tradição.

Portanto de acordo com o estudo feito por (FERREIRA; PINTO, 2010) os conceitos etnofarmacológicos e etnobotânicos podem mostrar e indentificar a sua história, aparti dos costumes trazidos pelos mais antigos da comunidade, e isso pôde-se concluir quando se vê espécies encontradas exóticas e nativas numa mesma comunidade.

Pode-se ver que é importante saber como as pessoas dessa comunidade adquiriram estes conhecimentos e como eles utilizam de forma corretamente essas plantas medicinais, pois consta na literatura que a maioria desses aprendizados vem da hereditariedade, ou seja, que vem passando de geração para geração. 
Tabela 1- Principais plantas medicinais do conhecimento dos alunos, com famílias botânicas, nomes científicos, nomes vernaculares, citações, parte utilizada, modo de preparo, indicação terapêutica e a validação do uso com artigos científicos sobre atividade medicinal. Fonte: Própria

\begin{tabular}{|c|c|c|c|c|c|c|}
\hline Família & Nome Científico & $\begin{array}{c}\text { Nome } \\
\text { Popular }\end{array}$ & $\begin{array}{c}\mathbf{N}^{0} \text { de } \\
\text { Citações }\end{array}$ & $\begin{array}{c}\text { Parte } \\
\text { Utilizada }\end{array}$ & $\begin{array}{l}\text { Modo de } \\
\text { Preparo }\end{array}$ & $\begin{array}{c}\text { Indicação } \\
\text { Terapêutica }\end{array}$ \\
\hline Apiaceae & $\begin{array}{c}\text { PimpinellaanisumL } \\
\text {. }\end{array}$ & Erva-doce & 1 & Frutos & Decocção & $\begin{array}{c}\text { Dor de } \\
\text { estomago/febr } \\
\mathrm{e} \\
\text { Calmante/dor } \\
\text { de barriga }\end{array}$ \\
\hline \multirow[t]{2}{*}{ Asteraceae } & $\begin{array}{c}\text { Achyroclinesaturei } \\
\text { oides(Lam.) DC }\end{array}$ & Marcela & 2 & Flor & Maceração & Dor de barriga \\
\hline & Matricaria recutita & Camomila & 3 & Flor & Decocção & Calmante \\
\hline Asteraceae & Cynarascolymus & Alcachofra & 2 & Folhas & & Diarréia \\
\hline \multirow[t]{5}{*}{ Lamiaceae } & Menthasp. & Hortelã & 3 & Folha & Decocção & $\begin{array}{c}\text { Tosse/gargant } \\
\text { a/gripe }\end{array}$ \\
\hline & Ocimumsp. & Alfavaca & 2 & Folha/casca & Infusão & Cicatrização \\
\hline & $\begin{array}{c}\text { Plectranthusbarbat } \\
\text { usAndrews }\end{array}$ & Boldo & 2 & Folha & Decocção & $\begin{array}{c}\text { Dor de } \\
\text { barriga/má } \\
\text { digestão }\end{array}$ \\
\hline & $\begin{array}{c}\text { Rosmarinusofficina } \\
\text { lisL }\end{array}$ & Alecrim & 2 & Folha & Decocção & Gripe \\
\hline & $\begin{array}{c}\text { ColeusbarbatusBen } \\
\text { th. }\end{array}$ & $\begin{array}{l}\text { Malva } \\
\text { Santa }\end{array}$ & 1 & Folha & Xarope & $\begin{array}{c}\text { Gripe/tosse/res } \\
\text { friado }\end{array}$ \\
\hline Myrtaceae & Eucalyptussp. & Eucalipto & 1 & Folha & Decocção & $\begin{array}{c}\text { Febre/gripe/si } \\
\text { nusite }\end{array}$ \\
\hline $\begin{array}{c}\text { Phyllantacea } \\
\text { e }\end{array}$ & PhyllanthusniruriL. & Quebra pedra & 1 & Raiz & Decocção & Pedra nos rins \\
\hline Poaceae & $\begin{array}{l}\text { Cymbopogoncitrat } \\
\text { us(DC) Stapf. }\end{array}$ & Capim-santo & 2 & Folhas & Decocção & $\begin{array}{c}\text { Calmante/ansi } \\
\text { edade }\end{array}$ \\
\hline Punicaceae & $\begin{array}{c}\text { Punica granatum } \\
\text { L. }\end{array}$ & Romã & 2 & $\begin{array}{l}\text { Semente/ca } \\
\text { sca }\end{array}$ & $\begin{array}{l}\text { Gargarejo } \\
\text { decocção }\end{array}$ & $\begin{array}{c}\text { Tosse/dor de } \\
\text { garganta }\end{array}$ \\
\hline $\begin{array}{c}\text { Amaranthac } \\
\text { eae }\end{array}$ & $\begin{array}{c}\text { Espanha } \\
\text { ambrosioides }\end{array}$ & Mentruz & 1 & Folhas & & $\begin{array}{c}\text { Anemia/Verm } \\
\text { es }\end{array}$ \\
\hline $\begin{array}{c}\text { Verbenacea } \\
\text { e }\end{array}$ & $\begin{array}{c}\text { Lippia alba (Mill.) } \\
\text { N.E. Br. }\end{array}$ & Erva-cidreira & 3 & Folha & Decocção & Dor de cabeça \\
\hline $\begin{array}{l}\text { Xanthorrhoe } \\
\text { aceae }\end{array}$ & $\begin{array}{c}\text { Aloe vera }(L .) \\
\quad \text { Burm. } f .\end{array}$ & Babosa & 2 & Folha & & $\begin{array}{l}\text { Queimaduras } \\
\text { na pele }\end{array}$ \\
\hline
\end{tabular}

\section{Conclusões}

Este estudo foi de suma importância para a população local porque contribuiu para a promoção da saúde das pessoas. As entrevistas foram fundamentais para a aproximação dos 
conhecimentos cultural e científico, assim como também serviram para instigar os moradores na implantação da horta medicinal comunitária. Com isto foi possível estimular e proporcionar aos moradores a utilização de plantas medicinais, contribuindo em parte para a resolução dos problemas locais sobre o acesso à Saúde.

\section{Referências}

ALICE, S.N. (2010). Bioma Caatinga. Embrapa, V.21, n.09, p.23-30.

CASTRO, M. S. (2008). Vigilância Sanitária: Desvendando o enigma, V. 43, n.12, p.53-58.

ELISABETSKY, E. Biodiversidades/Artigos. Etnofarmacologia, V.35, n. 47,p.10-20.

FREIRE, (1987). Direitos militantes. Pedagogia do Oprimido, V. 67, n.21, p. 130-134.

FERREIRA, O. P; PINTO, W. R, (2010). A Utilização de fitoterapia e de plantas medicinais. Estudos Fitoterápicos, V.32, n. 14, p. 43-46.

IBGE, (2016). Caracteristicas do município citado. Caracteristicas e Localidades, V. 65, n. 21, p. 45-49.

LOPEZ, P. D. (2012). Conhecimento sobre plantas medicinais. Rev. bras. Plantas med., V. 13 , n. 6 , p. 360-370.

OLIVEIRA, M. T. (2010). Estudo sobre Etnofarmacologia. Etnobio, V.06, n. 04, p.100-120.

OLIVEIRA, A. B. (2017) Utilidades sobre palntas medicinais. Biofarma, V. 07, N.02, P.8490 .

MATOS, B. T. (2011) Partes mais utilizadas das plantas medicinais. Farmavida, V. 76, N.74, P. 30-50.

MARINA, S. B. (2016) Conceito sobre o que são plantas medicinais. V. 10, n. 03, p.150.

MARTINEZ, B. G. (2015) Estudo sobre a manutenção de vida e saúde. V.01, n.04, p.55.

RODRIGUES, T. S. (2013) Estudos de plantas medicinais com relação a fitoterapia. V. 15, n. 10, p.20-21.

SANTOS, S. C. (2010) Conceito de etnofarmacologia e o uso de produtos bio ativos. 19, n. 12, p.94.

SILVA, T. Q. (2011) Estudo sobre o conceito de etnofarmacologia,Conceito de etnofarmacologia.V. 20, n. 21, p.36. 
SILVA, P. J. (2018) Instituto de saúde coletiva. SUS. V.98, n.76, p. 36-39.

SOUSSAN, P. T. (2003). Parâmetros Curriculares Nacionais.Os PCNs. V. 25, n. 33, p. 55-58.

VESTCON, A. Z. (2013). Constituição Federal 1988. V. 40, n. 41, p.300-310.

VIANA, L. V. (2016). A fitoterapia no mundo atual. Conhecimentos fitoterápicos. V.66, n. 44 , p. 37-40.

KAPLAN, S. P. (2010) Espécies mais utilizadas e conhecidas como medicamentos. Medicamentos mais utilizados. V. 30, n. 31, p.103-106. 